\title{
Risk factors and predictive value of perioperative neurocognitive disorders in elderly patients with gastrointestinal tumors
}

Yong-Li Li ${ }^{1}$, Hui-Fan Huang ${ }^{1}$ and Yuan Le $\mathrm{e}^{1,2^{*}}$

\begin{abstract}
Background: This study aims to investigate the risk factors of perioperative neurocognitive disorders (PNDs) mainly including postoperative cognitive dysfunction (POCD) in elderly patients with gastrointestinal tumors, and evaluate its predictive value.

Methods: A total of 222 eligible elderly patients ( $\geq 65$ years) scheduled for elective gastroenterectomy under general anesthesia were enrolled. The cognitive function assessment was carried out 1 day before surgery and 7 days after surgery. Receiver operating characteristic curve analysis was performed to evaluate the predictive value of risk factors for early POCD. The risk factors for POCD were analyzed using univariate and multivariate logistic regression model.

Results: Of all the 222 enrolled patients, 91 (41.0\%) developed early POCD and 40 (18.0\%) were identified as major POCD within 7 days after the surgery. Visual analogue score (VAS, 1st day, resting) $\geq 4$ (OR $=7.618[3.231-17.962], P<$ $0.001)$ and alcohol exposure $(\mathrm{OR}=2.398[1.174-4.900], P=0.016)$ were independent risk factors for early POCD. VAS score (1st, resting) $\geq 4$ ( $\mathrm{OR}=13.823[4.779-39.981], P<0.001$ ), preoperative white blood cell (WBC) levels $\geq 10 \times 10^{*} 9$ / $\mathrm{L}(\mathrm{OR}=5.548[1.128-26.221], P=0.035)$, blood loss $\geq 500 \mathrm{ml}(\mathrm{OR}=3.317[1.094-10.059], P=0.034)$, history of hypertension ( $\mathrm{OR}=3.046[1.267-7.322], P=0.013)$, and neutrophil-lymphocyte ratio $(\mathrm{NLR}) \geq 2$ (OR $=3.261[1.020-$ 10.419], $P=0.046)$ were independent risk factors for major POCD. Receiver operating characteristic curve analysis indicated that VAS score (1st day, resting) was a significant predictor for major POCD with a cut-off value of 2.68 and an area under the curve of 0.860 (95\% confidence interval: 0.801-0.920, $P<0.001$ ).

Conclusions: The risk factors for early POCD after gastroenterectomy included high VAS score (1st day, resting) and alcohol exposure. High VAS score, preoperative WBC levels $\geq 10 \times 10^{*} 9 / L$, blood loss $\geq 500 \mathrm{ml}$, NLR $\geq 2$, and history of hypertension were independent risk factors for major POCD. Among them, VAS score was one of the important predictors.
\end{abstract}

Keywords: Perioperative neurocognitive disorders, Postoperative cognitive dysfunction, Gastrointestinal tumors, Risk factors, Elderly

\footnotetext{
*Correspondence: leyuanxy@csu.edu.cn

'Department of Anesthesiology, the Third Xiangya Hospital, Central South University, No.138, Tongzipo Road, Yuelu District, Changsha 410013, Hunan, China

${ }^{2}$ Hunan Province Key Laboratory of Brain Homeostasis, The Third Xiangya Hospital, Central South University, No.138, Tongzipo Road, Yuelu District,

Changsha 410013, Hunan, China
}

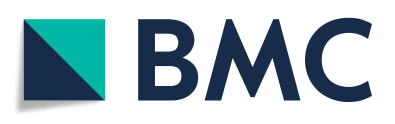

(C) The Author(s). 2021 Open Access This article is licensed under a Creative Commons Attribution 4.0 International License, which permits use, sharing, adaptation, distribution and reproduction in any medium or format, as long as you give appropriate credit to the original author(s) and the source, provide a link to the Creative Commons licence, and indicate if changes were made. The images or other third party material in this article are included in the article's Creative Commons licence, unless indicated otherwise in a credit line to the material. If material is not included in the article's Creative Commons licence and your intended use is not permitted by statutory regulation or exceeds the permitted use, you will need to obtain permission directly from the copyright holder. To view a copy of this licence, visit http://creativecommons.org/licenses/by/4.0/ The Creative Commons Public Domain Dedication waiver (http://creativecommons.org/publicdomain/zero/1.0/) applies to the data made available in this article, unless otherwise stated in a credit line to the data. 


\section{Background}

Postoperative cognitive disorders (PNDs) is a kind of impairment in cognitive ability which is the most common complication experienced in the postoperative period by these elderly individuals [1-4]. PNDs includes postoperative delirium (POD) and postoperative cognitive dysfunction (POCD) [4]. POD occurs hours to days after surgery and is characterized by cognitive deficits in executive function, memory, and other cognitive domains, with most symptoms resolving in weeks to months [1]. According to previous studies, the incidence of POD in non-cardiac surgery is $13-50 \%$ [5]. Delirium is associated with the need for supportive postoperative care, progression to dementia, and increased mortality risk, healthcare costs [6-9]. POCD is cognitive decline performed predominantly in executive function and memory domains of cognition. The incidence of POCD is reported to range from 17 to $43 \%$ [10]. Previous clinical studies have identified age, inflammation, and preoperative cognitive disorders as potential risk factors for PNDs [1]. PNDs are measured by a battery of neuropsychological tests, but with a range of criteria. At present, there are still many controversies about the pathological mechanism and treatment of PNDs. Therefore, identifying and avoiding its risk factors may be an effective strategy.

Gastrointestinal tumors mainly include gastric cancer and colorectal cancer. Gastric carcinoma (GC) is the fourth most common malignant tumor and remains the second most deadly cancer of all malignancies worldwide [11-13]. Colorectal cancer (CRC) is the world's fourth cause of death cancer with almost 900,000 deaths annually [14]. The incidence of gastrointestinal tumors varies geographically with the highest rates seen in the most developed countries. Gastrointestinal tumors have caused a serious global financial medical burden [15-17]. In epidemiological studies, smoking, excessive alcohol intake, obesity, red and processed meat intake, type 2 diabetes and increasing age have shown strong associations with disease incidence. Both hereditary and environmental play an important part in the development of disease [11, 14]. Treatments include endoscopic and surgical therapy, radiotherapy and systemic therapy, and palliative chemotherapy, targeted therapy, and immunotherapy [11-14]. The elderly patients are vulnerable to PNDs after surgery. However, the risk factors for PNDs in patients with gastrointestinal tumors remain unclear. This study aimed to reveal the potential risk factors for PNDs in elderly patients with gastrointestinal tumors and evaluate their predictive value.

\section{Methods}

\section{Patients}

The present study protocol was approved by the Ethics Committee of the Third Xiangya Hospital (ID:21011). All methods were performed in accordance with the relevant guidelines and regulations. Elderly patients with gastrointestinal tumors (aged $\geq 65$ years) who were scheduled for selective Gastroenterectomy under general anesthesia in our hospital from January 2018 to June 2020 were enrolled in this study. Inclusion criteria were: (1) Preoperative Mini-Mental State Examination (MMSE) scores $\geq 24$ points; (2) aged $\geq 65$ years; (3) patient was scheduled for elective Gastroenterectomy under general anesthesia. In addition, the exclusion criteria were as follows: (1) history of severe neurological or psychiatric disease; (2) history of tranquilizers or antidepressants medication; (3) serious audio-visual impairments that affected assessments; (4) patients diagnosed with delirium by using CAM before surgery.

\section{Data collection}

The following data were collected: (1) demographics and clinical baseline data, including age, gender, education, and body mass index (BMI), American Society of Anesthesiologists grade (ASA), MMSE score, smoking or drinking habits, medical history; (2) main clinicopathological parameters, including the type of surgery, operation time and estimated blood loss, perioperative insulation, VAS score (1st, 2nd, 7th day after surgery, resting and activity), EQ-5D score (7th, 30th day after surgery), grip strength, transverse abdominis plane block (TAP), intensive care unit (ICU) therapy, pharmacotherapy (Non-steroidal anti-inflammatory drugs, Dexmedetomidine, etc.); (3) laboratory tests, including the blood cell analysis which was carried out 1 day before surgery and 1 day after surgery, albumin (Alb), creatinine levels, preoperative serum potassium levels $\left(\mathrm{K}^{+}\right.$levels).

\section{Cognitive function measurement}

The cognitive function assessment was carried at baseline ( 1 day before the surgery) and at day 7 after the surgery, independently by two experienced anesthesia nurses who were blinded to this protocol. The two anesthesia nurses were professionally trained, and performed Kappa tests for the diagnostic results of POD and POCD before recruiting patients. Delirium was assessed once on preoperatively 1 day and twice daily at $10 \mathrm{am}$ and $6 \mathrm{pm}$ from postoperatively day 1 to day 7 using the CAM scale. The battery of neuropsychological tests consisted of mini-mental state examination (MMSE) and the confusion assessment method (CAM). As described by previous Studies, POCD was diagnosed when the MMSE score was lower than 1 standard deviation (SD) compared with the baseline score. A decrease 
of more than 2 SD in MMSE score was diagnosed as severe cognitive impairment. A decrease in MMSE score of 1 to $<2$ SD indicated mild POCD [2, 18, 19].

\section{Statistical analysis}

Data analysis was performed using SPSS 25.0 (SPSS Inc., Chicago, IL). Categorical and continuous data were expressed as number (with percentage, $\mathrm{n} \%$ ) and mean (with standard deviation). Intergroup rates were compared using the chi-square test or Fisher's test. Relative risk was represented by odds ratio (OR) and its $95 \%$ confidence interval (CI). Student's t test or analysis of variance were used to compare the continuous data between groups according to the data. Repeated measure analysis of variance was used to statistically analyze the VAS scores of the two groups at each period after surgery. The risk factors were analyzed by univariate and multivariate binary Logistic regression analysis. Univariate Logistic regression analysis was used to select independent variables, and relevant factors of $P$ value $\leq 0.15$ in univariate analysis were included in the multivariate binary Logistic regression model to analyze the risk factors of perioperative cognitive dysfunction in elderly patients with gastrointestinal tumor. Enter method was used, and $P$ value $<0.05$ was considered statistically significant. Receiver-operating characteristic curve (ROC) analysis was conducted to assess the predictive value of risk factors for early POCD. The cut-off point value is calculated according to the maximum value of Youden's index. Statistical significance was set as bilateral $P$ value $<0.05$. For a small amount of missing data, using the method of average fill for statistical analysis.

\section{Results}

Demographics and clinical baseline data

A total of 222 elderly patients ( $\geq 65$ years old) with gastrointestinal tumors were included in the final analysis. 91 of them were identified as early POCD with an incidence of $40.99 \%$ (91 of 222) and 40 cases were diagnosed with severe POCD with an incidence of $18.02 \%$ (40 of 222). Only 3 of them were diagnosed as POD with an incidence of $1.35 \%$ (3 of 222). As the incidence of POD was too low and the existing sample size was too small, the risk factors of POD were not further analyzed. The demographic and clinical characteristics of the patients with or without POCD were summarized in Table 1. Patients with chronic smoking habits $(P=$

Table 1 Demographics and Clinical data associated with POCD in elderly patients with gastrointestinal tumors

\begin{tabular}{|c|c|c|c|}
\hline Item & POCD group $(n=91)$ & Non-POCD group $(n=131)$ & $P$-value \\
\hline Age (y) & $70.57 \pm 4.24$ & $70.91 \pm 5.10$ & 0.605 \\
\hline Male $(n, \%)$ & $61(67.0 \%)$ & $95(72.5 \%)$ & 0.379 \\
\hline BMI $\left(\mathrm{kg} \cdot \mathrm{m}^{-2}\right)$ & $21.81 \pm 2.70$ & $22.47 \pm 3.17$ & 0.105 \\
\hline ASA $(n, \%)$ & & & 0.097 \\
\hline II & $21(23.1 \%)$ & $39(29.8 \%)$ & \\
\hline III & $70(76.9 \%)$ & $89(67.9 \%)$ & \\
\hline IV & $0(0.0 \%)$ & $3(2.3 \%)$ & \\
\hline Education $(n, \%)$ & & & 0.758 \\
\hline Illiteracy & $4(4.4 \%)$ & $6(4.6 \%)$ & \\
\hline Elementary school & $42(46.2 \%)$ & $62(47.3 \%)$ & \\
\hline High school & $41(45.1 \%)$ & $53(40.5 \%)$ & \\
\hline College or higher & $4(4.4 \%)$ & $10(7.6 \%)$ & \\
\hline Preoperative MMSE score & $26.98 \pm 1.70$ & $26.63 \pm 1.81$ & 0.154 \\
\hline \multicolumn{4}{|l|}{ Medical history $(n, \%)$} \\
\hline Hypertension & $39(42.9 \%)$ & $53(40.5)$ & 0.721 \\
\hline Diabetes & $13(14.3 \%)$ & $20(15.3 \%)$ & 0.840 \\
\hline Cerebrovascular disease & $10(11 \%)$ & $11(8.4 \%)$ & 0.516 \\
\hline Cardiovascular disease & $11(12.1 \%)$ & $17(13 \%)$ & 0.844 \\
\hline Lung disease & $38(41.8)$ & 44(33.6) & 0.215 \\
\hline Chemotherapy & $5(5.5 \%)$ & $2(1.5 \%)$ & 0.126 \\
\hline Smoking $(n, \%)$ & $40(44 \%)$ & $37(28.2)$ & $0.016^{*}$ \\
\hline Alcohol consumption ( $n, \%)$ & $24(26.4 \%)$ & $19(14.5 \%)$ & $0.028^{*}$ \\
\hline
\end{tabular}

Notes: Abbreviations: ASA American Society of Anesthesiologists, BMI Body mass index, MMSE Mini-mental State Examination, POCD Postoperative cognitive dysfunction * $P<0.05$ 
$0.016)$ or alcohol consumption $(P=0.028)$ were more likely to suffer from early POCD. No significant differences were observed between POCD and non-POCD groups concerning age, gender, BMI, ASA status, education levels, pre-MMSE score, and medical history $(P>$ $0.05)$.

\section{Main clinical data and laboratory tests}

As shown in Table 2 and Fig. 1, a higher VAS score $(P<$ 0.001 ) was significantly correlated with the development of POCD. Compared with the non-POCD group, POCD patients had lower serum potassium levels before surgery $(P=0.045)$ and EQ-5D scores on 30 days after surgery $(P=0.047)$. No statistical differences were found in the WBC levels, hemoglobin $(\mathrm{Hb})$, albumin, operation time, blood loss, warm treatment, grip strength, pharmacotherapy (Non-steroidal anti-inflammatory drugs, Dexmedetomidine, etc.) between the POCD and non-POCD group $(P>0.05)$. Although there was no statistical difference in postoperative ICU therapy rate between POCD patients and non-POCD patients, the $P$ value was very close to the threshold value of $0.05(P=0.07)$.

When POCD patients were further stratified into mild and severe patients, as displayed in Table 3, it was found

Table 2 Main clinical data and laboratory tests associated with POCD in elderly patients with gastrointestinal tumors

\begin{tabular}{|c|c|c|c|}
\hline Item & POCD group $(n=91)$ & Non-POCD group $(n=131)$ & $P$-value \\
\hline \multicolumn{4}{|l|}{ VAS score } \\
\hline 1st day after surgery (resting) & $3.49 \pm 1.52$ & $1.58 \pm 1.43$ & $0.000^{*}$ \\
\hline 1st day after surgery (activity) & $4.40 \pm 1.36$ & $3.28 \pm 1.21$ & $0.000^{*}$ \\
\hline 2nd day after surgery (resting) & $1.21 \pm 1.11$ & $1.27 \pm 1.21$ & 0.741 \\
\hline 2nd day after surgery (activity) & $3.10 \pm 1.31$ & $3.07 \pm 1.08$ & 0.812 \\
\hline 7th day after surgery (resting) & $2.24 \pm 1.66$ & $1.87 \pm 1.39$ & 0.073 \\
\hline 7th day after surgery (activity) & $3.18 \pm 1.44$ & $2.79 \pm 1.48$ & 0.050 \\
\hline 1 st day after surgery (resting) $\geq 4$ & $28(30.8 \%)$ & $8(6.1 \%)$ & $0.000^{*}$ \\
\hline \multicolumn{4}{|l|}{ EQ-5D score } \\
\hline Preoperative EQ-5D score & $82.48 \pm 9.93$ & $81.30 \pm 12.62$ & 0.434 \\
\hline 7th day after surgery & $64.92 \pm 15.73$ & $68.87 \pm 13.87$ & 0.050 \\
\hline 30th day after surgery & $68.36 \pm 20.14$ & $72.99 \pm 14.34$ & $0.047^{*}$ \\
\hline Operation time (min) & $237.02 \pm 90.06$ & $225.21 \pm 74.87$ & 0.289 \\
\hline Blood loss (ml) & $282.20 \pm 40.59$ & $198.63 \pm 21.29$ & 0.070 \\
\hline$>1000 \mathrm{ml}$ & $6(6.6 \%)$ & $2(1.5 \%)$ & 0.066 \\
\hline TAP & $37(40.7 \%)$ & $48(36.6 \%)$ & 0.545 \\
\hline Warm treatment & $67(73.6 \%)$ & 104(79.4\%) & 0.315 \\
\hline Grip strength & $24.08 \pm 6.67$ & $25.48 \pm 6.98$ & 0.136 \\
\hline ICU therapy & $11(12.1 \%)$ & $7(5.3 \%)$ & 0.070 \\
\hline \multicolumn{4}{|l|}{ Pharmacotherapy } \\
\hline NSAIDs & $11(12.1 \%)$ & 18(13.7\%) & 0.719 \\
\hline Dexmedetomidine & $30(33 \%)$ & $48(36.6 \%)$ & 0.573 \\
\hline \multicolumn{4}{|l|}{ Laboratory tests } \\
\hline $\mathrm{K}^{+}$levels (mmol/L) & $3.38 \pm 0.47$ & $3.51 \pm 0.48$ & $0.045^{*}$ \\
\hline Pre-WBC levels $\left(\times 10^{9} / L\right)$ & $6.19 \pm 2.14$ & $6.22 \pm 1.92$ & 0.900 \\
\hline Post-WBC levels $\left(\times 10^{9} / \mathrm{L}\right)$ & $10.56 \pm 3.64$ & $11.43 \pm 3.82$ & 0.093 \\
\hline WBC gap & $4.65 \pm 3.07$ & $4.98 \pm 3.08$ & 0.432 \\
\hline Albumin (g/L) & $38.24 \pm 4.81$ & $38.11 \pm 4.25$ & 0.842 \\
\hline $\mathrm{Hb}$ levels & $116.17 \pm 23.76$ & $115.88 \pm 23.85$ & 0.930 \\
\hline $\operatorname{NLR} \geq 2$ & $65(71.4 \%)$ & $91(69.5 \%)$ & 0.753 \\
\hline
\end{tabular}

Notes: For a small amount of missing data (loss rate $<5 \%$ ), using the method of average fill for statistical analysis. Abbreviations: VAS Visual analogue $5 c o r e, E Q-5 D$ quality-of-life EuroQol-5 Dimensions, TAP transverse abdominis plane block, ICU Intensive care unit, NSAIDS Non-steroidal anti-inflammatory drugs, WBC levels White blood cells levels, WBC gap |post-WBC levels - pre-WBC levels|, Hb Hemoglobin, $K+$ levels preoperative serum potassium levels, MMSE Mini-mental State Examination, $P O C D$ Postoperative cognitive dysfunction $* P<0.05$ 

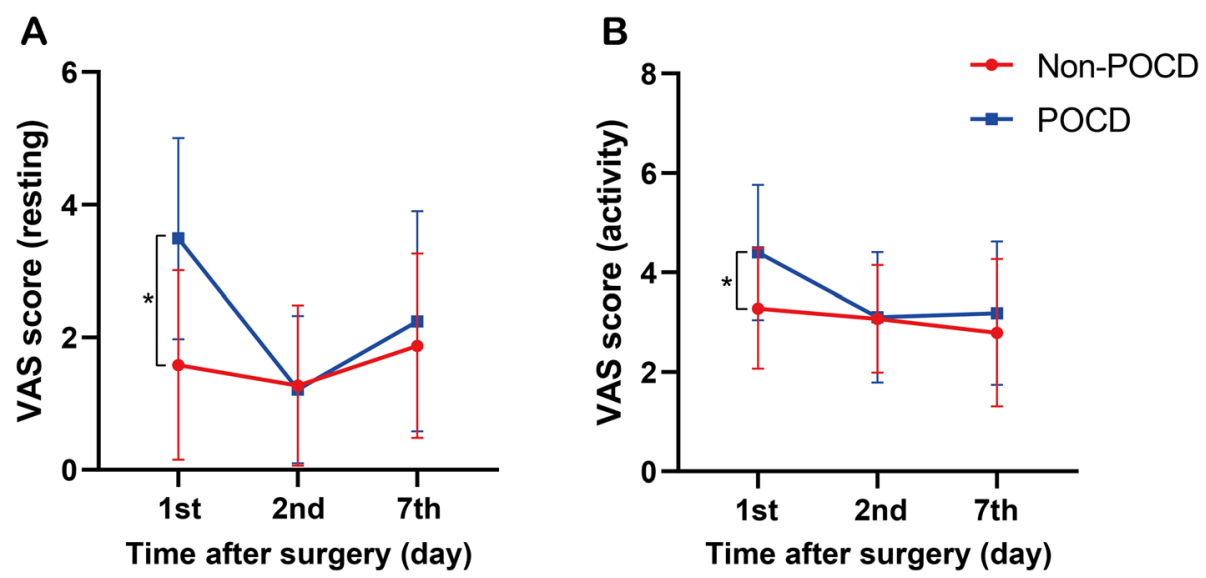

Fig. 1 A-B: Postoperative VAS score and POCD. VAS: visual analogue score; POCD: postoperative cognitive dysfunction; * $P<0.05$.

that in addition to insufficient analgesia, history of hypertension, surgical blood loss of $\geq 500 \mathrm{ml}$, and patients with NLR $\geq 2$ were more likely to develop into severe cognitive impairment $(P<0.05)$. Patients with severe postoperative cognitive impairment were more likely to be treated in the ICU during this hospitalization $(P=0.024) . P$ value for preoperative $\mathrm{WBC}$ level $\geq 10 \times$ $10 * 9 / \mathrm{L}$ was close to $0.05(P=0.051)$.

\section{Risk factors associated with POCD}

The risk factors were analyzed by univariate and multivariate binary Logistic regression analysis. Univariate Logistic regression analysis was used to select independent variables, and relevant factors of $P$ value $\leq 0.15$ in univariate analysis were included in the multivariate binary Logistic regression model to analyze the risk factors of perioperative cognitive dysfunction in elderly patients with gastrointestinal tumor. Enter method was used, and $P$ value $<0.05$ was considered statistically significant. Supplementary Table 1 and supplementary table 2

Table 3 Clinicopathological parameters associated with major POCD in elderly patients with gastrointestinal tumors

\begin{tabular}{|c|c|c|c|c|}
\hline Item & $\begin{array}{l}\text { Major POCD } \\
\text { group } \\
(n=40)\end{array}$ & $\begin{array}{l}\text { Mild POCD } \\
\text { group } \\
(n=51)\end{array}$ & $\begin{array}{l}\text { Non-POCD } \\
\text { group } \\
(n=131)\end{array}$ & $P$-value \\
\hline Hypertension & $23(57.5 \%)$ & $16(31.4 \%)$ & $53(40.5 \%)$ & $0.040^{*}$ \\
\hline ICU therapy & $8(20.0 \%)$ & $3(5.9 \%)$ & $7(5.3 \%)$ & $0.024^{*}$ \\
\hline $\begin{array}{l}\text { Pre-WBC levels } \geq \\
10\left(\times 10^{9} / \mathrm{L}\right)\end{array}$ & $5(12.5 \%)$ & 2(3.9\%) & $3(2.3 \%)$ & 0.051 \\
\hline $\begin{array}{l}\text { VAS ( } 1 \text { st day, } \\
\text { resting) } \geq 4\end{array}$ & $16(40 \%)$ & $12(23.5 \%)$ & $8(6.1 \%)$ & $0.000^{*}$ \\
\hline Blood loss $\geq 500 \mathrm{ml}$ & $9(22.5 \%)$ & $3(5.9 \%)$ & 13(9.9\%) & $0.034^{*}$ \\
\hline$N L R \geq 2$ & $35(87.5 \%)$ & $30(58.8 \%)$ & $91(69.5 \%)$ & $0.012^{*}$ \\
\hline
\end{tabular}

Notes: Abbreviations: ICU Intensive care unit, Pre-WBC Preoperative white blood cell, VAS Visual analogue score, NLR Neutrophil-lymphocyte ratio, POCD Postoperative cognitive dysfunction

* $P<0.05$ showed the risk factors associated with POCD or major POCD in elderly patients with gastrointestinal tumors by univariate logistic regression analysis. Table 4 and Table 5 summarized the potential independent risk factors between the POCD and non-POCD groups. The results revealed that VAS score (1st day, resting) $\geq 4$ points and alcohol exposure were the independent risk factors associated with POCD. Furthermore, VAS score $\geq 4$ points, blood loss $>500 \mathrm{ml}$, preoperative white blood cell count $\geq 10 \times 10^{*} 9 / \mathrm{L}, \mathrm{NLR} \geq 2$, and history of hypertension were independent risk factors for severe cognitive impairment in elderly patients with gastrointestinal tumors.

\section{VAS score and POCD}

Receiver-operating characteristic curve analysis was conducted to investigate the predictive value of risk factors for early major POCD. As listed in Fig. 2, the area under the curve of VAS score for POCD was 0.860, with the cut-off value of 2.68 , sensitivity of $87.5 \%$, and specificity of $74.8 \%$ respectively (95\% confidence interval: $0.801-$ $0.920, P<0.001$ ). The ROC analysis of blood loss (AUC: $0.614, P=0.052$ ) and NLR (AUC: $0.644, P=0.047$ ) showed poor predictive performance.

Table 4 Risk factors associated with POCD in elderly patients with gastrointestinal tumors by multivariate logistic regression analysis

\begin{tabular}{lllll}
\hline $\begin{array}{l}\text { Predictive factors } \\
\text { of POCD }\end{array}$ & OR & \multicolumn{2}{l}{$\mathbf{9 5 \%}$ Confidence interval } & $P$-value \\
\cline { 3 - 4 } & & Lower & Upper & \\
\hline VAS (1st day, resting) $\geq \mathbf{4}$ & 7.618 & 3.231 & 17.962 & $0.000^{*}$ \\
Alcohol consumption & 2.398 & 1.174 & 4.900 & $0.016^{*}$ \\
Blood loss $\geq \mathbf{1 0 0 0} \mathbf{~ m l}$ & 5.308 & 0.998 & 28.242 & 0.050 \\
\hline
\end{tabular}

Notes: Abbreviations: VAS Visual analogue score, POCD Postoperative cognitive dysfunction, $O R$ Odds ratio

$* P<0.05$ 
Table 5 Risk factors associated with major POCD in elderly patients with gastrointestinal tumors by multivariate logistic regression analysis

\begin{tabular}{lllll}
\hline $\begin{array}{l}\text { Predictive factors } \\
\text { of POCD }\end{array}$ & OR & \begin{tabular}{l}
$l$ \\
\multicolumn{9}{l}{$\begin{array}{l}\text { 95\% Confidence } \\
\text { interval }\end{array}$}
\end{tabular} & P-value \\
\cline { 2 - 4 } & & Lower & Upper & \\
\hline VAS (1 st day, resting) $\geq \mathbf{4}$ & 13.823 & 4.779 & 39.981 & $0.000^{*}$ \\
Pre-WBC levels $\geq \mathbf{1 0}$ & 5.438 & 1.128 & 26.221 & $0.035^{*}$ \\
Blood loss $\geq \mathbf{5 0 0 ~} \mathbf{~ m l}$ & 3.317 & 1.094 & 10.059 & $0.034^{*}$ \\
Hypertension & 3.046 & 1.267 & 7.322 & $0.013^{*}$ \\
NLR $\geq \mathbf{2}$ & 3.261 & 1.020 & 10.419 & $0.046^{*}$ \\
\hline
\end{tabular}

Notes: Abbreviations: VAS Visual analogue score, Pre-WBC levels Preoperative white blood cell, NLR Neutrophil-lymphocyte ratio, $P O C D$ Postoperative cognitive dysfunction, $O R$ Odds ratio

${ }^{*} P<0.05$

\section{Discussion}

In the present study, we found that the incidence of POCD was calculated to be 41.0 and $18.0 \%$ were identified as major POCD within 7 days after the surgery, which was in accordance with the 17 to $43 \%$ by Evered L et al. [10] The results from our study indicated high VAS score, hypertension, preoperative gastrointestinal tumors. Patients with major POCD were more likely to be treated in the ICU during this hospitalization and related to poor EQ-5D scores on day 30.

PNDs are common postoperative complications after major surgery with unknown exact pathophysiology in the elderly over 65 years old [1,20]. Previous studies have identified age, lower level of education, inflammation, postoperative pain, serum $25(\mathrm{OH}) \mathrm{D}$ level and preoperative cognitive disorders as potential risk factors for PNDs [21-25]. However, it isn't exactly in accordance with our results. Our results from multivariate logistic analysis did not support the predictive value of age and lower level of education. The relatively small age range and different types of surgery may attribute to the difference. Our study revealed that perioperative pain management and infection control may be an important link to avoid the occurrence of PNDS. Interestingly, Halazun et al. [26] and Yong, R. et al. [27] have also reported the predictive role of preoperative NLR for POCD. However, the cut-off value of NLR for POCD in their results were 5.0 and 2.5, which was quite different from our study (2.0). NLR is calculated from neutrophils and lympho-

\section{Risk factors for major POCD by ROC curve}

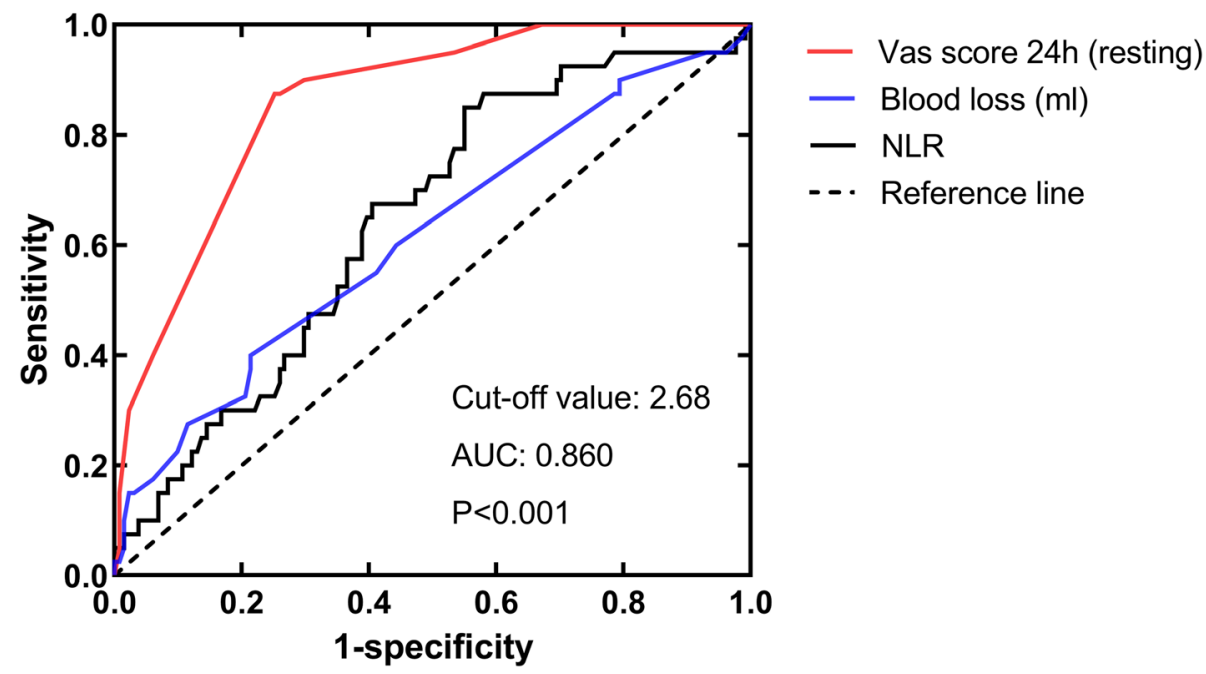

Fig. 2 Predictive value of risk factors for early major POCD in elderly patients with gastrointestinal tumors by ROC curve analysis. The area under the curve (AUC) of VAS score for POCD was 0.860 , with the cut-off value of 2.68 , sensitivity of $87.5 \%$ and specificity of $74.8 \%$, respectively ( $95 \%$ Cl: 0.801-0.920, P < 0.001). ROC: receiver operating characteristic; NLR: neutrophil-lymphocyte ratio; AUC: area under the curve; Cl: confidence interval; POCD: postoperative cognitive dysfunction

WBC levels of $\geq 10 \times 10 * 9 / \mathrm{L}$, surgical blood loss of $\geq 500 \mathrm{ml}$, and patients with NLR $\geq 2$ were independent risk factors for major POCD in elderly patients with gastrointestinal tumors. VAS score was one of the important predictors. Multimodal analgesia and inflammation control may be effective suggestions to minimize the POCD in elderly patients with cytes, which is considered as a prognostic factor in patients with numerous diseases, such as lung cancer, colorectal cancer, coronary artery bypass grafting, Alzheimer's disease and cardiovascular disease [28-32]. As a predictor of disease, NLR is not very specific, but it reveals that inflammation may play an important role in many diseases. 
Our results provide a few suggestions to minimize the POCD in elderly patients with gastrointestinal tumors, but we only investigated the risk factors for POCD in the early postoperative period. Previous studies have failed to show an association between cognitive dysfunction lasting months to years after surgery and the anaesthesia itself. At present, relatively few long-term prospective studies have been published, and relevant researches are needed [33-38].

\section{Limitations}

The study has some limitations. First, MMSE, the perioperative cognitive function assessment scale used in this study, has some limitations and its efficacy in screening mild cognitive function is insufficient. Second, the international academic community usually evaluates PND with a combination of neuropsychological tests, but this method is very complex and patients have poor coordination. Therefore, the cognitive assessment tools used in large sample clinical studies need to be further studied. Lastly, multicentre clinical big data and observational studies are needed to determine whether the current risk factors have high predictive value.

\section{Conclusions}

In conclusion, the incidence of POCD is relatively high in elderly patients with gastrointestinal tumors. The risk factors for early POCD after gastroenterectomy included a high resting VAS score on the first day after surgery and alcohol exposure. High VAS score, preoperative WBC levels $\geq 10 \times 10 * 9$, blood loss $\geq 500 \mathrm{ml}$, NLR $\geq 2$, and history of hypertension were independent risk factors for major POCD among which VAS score was one of the important predictors.

\section{Abbreviations}

PNDs: Perioperative neurocognitive disorders; POCD: Postoperative cognitive dysfunction; POD: Postoperative delirium

\section{Supplementary Information}

The online version contains supplementary material available at https://doi. org/10.1186/s12871-021-01405-7

Additional file 1: Table S1. Risk factors associated with POCD in elderly patients with gastrointestinal tumors by univariate logistic regression analysis.

Additional file 2: Table S2. Risk factors associated with major POCD in elderly patients with gastrointestinal tumors by univariate logistic regression analysis

\section{Acknowledgments}

Not applicable.

\section{Authors' contributions}

YL conducted the study and revised the manuscript. YLL collected the data, analyzed the data and wrote the manuscript. HFH collected the data. All authors read and approved the final manuscript.
Funding

The National Natural Science Foundation of China (No.81870861).

Availability of data and materials

The datasets generated and analyzed during the current study are available from the corresponding author on reasonable request.

\section{Declarations}

Ethics approval and consent to participate

The present study was approved by the Ethics Committee of the Third Xiangya Hospital (ID:21011). All methods were performed in accordance with the 1964 Helsinki declaration and its later amendments or comparable ethical standards. Because of retrospective study, informed consent was waived by the Ethics Committee of the Third Xiangya Hospital.

Consent for publication

Not applicable.

\section{Competing interests}

The authors declare that they have no competing interests.

Received: 16 February 2021 Accepted: 17 June 2021

Published online: 19 July 2021

\section{References}

1. Eckenhoff RG, Maze M, Xie Z, Culley DJ, Goodlin SJ, Zuo Z, et al. Perioperative Neurocognitive Disorder State of the Preclinical Science. Anesthesiology. 2020;132(1):55.

2. Mahanna-Gabrielli E, Schenning KJ, Eriksson LI, Browndyke JN, Wright CB, Evered L, et al. State of the clinical science of perioperative brain health: report from the American Society of Anesthesiologists Brain Health Initiative Summit 2018. Br J Anaesth. 2019;123(4):464-78. https://doi.org/10.1016/j. bja.2019.07.004.

3. Daiello LA, Racine AM, Gou RY, Marcantonio ER, Xie Z, Kunze LJ, et al. Postoperative delirium and postoperative cognitive dysfunction overlap and divergence. Anesthesiology. 2019;131(3):477-91. https://doi.org/10.1097/A LN.0000000000002729.

4. Evered L, Silbert B, Knopman DS, Scott DA, DeKosky ST, Rasmussen LS, et al. Recommendations for the nomenclature of cognitive change associated with anaesthesia and surgery-2018. Br J Anaesth. 2018;121(5):1005-12. https://doi.org/10.1016/j.bja.2017.11.087.

5. Inouye SK, Westendorp RGJ, Saczynski JS. Delirium in elderly people. Lancet. 2014;383(9920):911-22. https://doi.org/10.1016/S0140-6736(13)60688-1.

6. Sprung J, Roberts RO, Weingarten TN, Cavalcante AN, Knopman DS, Petersen RC, et al. Postoperative delirium in elderly patients is associated with subsequent cognitive impairment. Br J Anaesth. 2017:119(2):316-23. https://doi.org/10.1093/bja/aex130.

7. Sauer AC, Veldhuijzen DS, Ottens TH, Slooter AJC, Kalkman CJ, van Dijk D. Association between delirium and cognitive change after cardiac surgery. Br J Anaesth. 2017;119(2):308-15. https://doi.org/10.1093/bja/aex053.

8. Hamilton GM, Wheeler K, Di Michele J, Lalu MM, Mclsaac DI. A systematic review and meta-analysis examining the impact of incident postoperative delirium on mortality. Anesthesiology. 2017:127(1):78-88. https://doi.org/1 0.1097/ALN.0000000000001660

9. Rudolph JL, Marcantonio ER. Postoperative delirium: acute change with long-term implications. Anesth Analg. 2011;112(5):1202-11. https://doi.org/1 0.1213/ANE.0b013e3182147f6d.

10. Evered L, Scott DA, Silbert B, Maruff P. Postoperative cognitive dysfunction is independent of type of surgery and anesthetic. Anesth Analg. 2011; 112(5):1179-85. https://doi.org/10.1213/ANE.0b013e318215217e.

11. Sitarz R, Skierucha M, Mielko J, Offerhaus GJA, Maciejewski R, Polkowski WP. Gastric cancer: epidemiology, prevention, classification, and treatment. Cancer Manag Res. 2018;10:239-48. https://doi.org/10.2147/CMAR.S149619.

12. Karimi P, Islami F, Anandasabapathy S, Freedman ND, Kamangar F. Gastric Cancer: descriptive epidemiology, risk factors, screening, and prevention. Cancer Epidemiol Biomark Prev. 2014:23(5):700-13. https://doi.org/10.1158/1 055-9965.EPI-13-1057.

13. Guggenheim DE, Shah MA. Gastric cancer epidemiology and risk factors. Surg Oncol. 2013;107(3):230-6. https://doi.org/10.1002/jso.23262. 
14. Dekker E, Tanis PJ, Vleugels JLA, Kasi PM, Wallace MB. Colorectal cancer. Lancet. 2019;394(10207):1467-80. https://doi.org/10.1016/S0140-6736(1 9)32319-0.

15. Thrift AP, El-Serag HB. Burden of gastric Cancer. Clin Gastroenterol Hepatol. 2020;18(3):534-42. https://doi.org/10.1016/j.cgh.2019.07.045.

16. Peery AF, Crockett SD, Murphy CC, Lund JL, Dellon ES, Williams $J$, et al. Burden and Cost of Gastrointestinal, Liver, and Pancreatic Diseases in the United States: Update 2018. Gastroenterology. 2019;156(1):254.

17. Keum N, Giovannucci E. Global burden of colorectal cancer: emerging trends, risk factors and prevention strategies. Nat Rev Gastroenterol Hepatol. 2019;16(12):713-32. https://doi.org/10.1038/s41575-019-0189-8.

18. Mathew JP, White WD, Schinderle DB, Podgoreanu MV, Berger M, Milano CA, et al. Intraoperative magnesium administration does not improve neurocognitive function after cardiac surgery. Stroke. 2013;44(12):3407-13. https://doi.org/10.1161/STROKEAHA.113.002703.

19. Newman MF, Kirchner JL, Phillips-Bute B, Gaver V, Grocott H, Jones RH, et al. longitudinal assessment of neurocognitive function after coronary-artery bypass surgery. N Engl J Med. 2001;344(6):395-402. https://doi.org/10.1056/ NEJM200102083440601.

20. Chan MTV, Cheng BCP, Lee TMC, Gin T, Grp CT. BIS-guided anesthesia decreases postoperative delirium and cognitive decline. J Neurosurg Anesthesiol. 2013;25(1):33-42. https://doi.org/10.1097/ANA.0b013e3182712 fba.

21. Tsai $T L$, Sands LP, Leung JM. An update on postoperative cognitive dysfunction. Adv Anesth. 2010;28(1):269-84. https://doi.org/10.1016/j.aan.201 0.09.003.

22. Wang $Y$, Sands LP, Vaurio L, Mullen EA, Leung JM. The effects of postoperative pain and its management on postoperative cognitive dysfunction. Am J Geriatr Psychiatr. 2007;15(1):50-9. https://doi.org/10.1097/ 01.JGP.0000229792.31009.da.

23. Brien $\mathrm{HO}$, Mohan $\mathrm{H}$, Hare CO, Reynolds JV, Kenny RA. Mind over matter? The hidden epidemic of cognitive dysfunction in the older surgical patient. Ann Surg. 2017;265(4):677-91. https://doi.org/10.1097/SLA.0000000000001 900.

24. Gao B, Zhu B, Wu C. Preoperative serum 25-Hydroxyvitamin D level, a risk factor for postoperative cognitive dysfunction in elderly subjects undergoing Total joint Arthroplasty. Am J Med Sci. 2019;357(1):37-42. https://doi.org/10.1016/j.amjms.2018.10.012.

25. Zhang Y, Bao HG, Lv YL, Si YN, Han L, Wang HY, et al. Risk factors for early postoperative cognitive dysfunction after colorectal surgery. BMC Anesthesiol. 2019;19(1):6. https://doi.org/10.1186/s12871-018-0676-4.

26. Halazun HJ, Mergeche JL, Mallon KA, Connolly ES, Heyer EJ. Neutrophillymphocyte ratio as a predictor of cognitive dysfunction in carotid endarterectomy patients. J Vasc Surg. 2014;59(3):768-73. https://doi.org/10.1 016/j.jvs.2013.08.095.

27. Yong R, Meng Y. Preoperative neutrophil-lymphocyte ratio, an independent risk factor for postoperative cognitive dysfunction in elderly patients with gastric cancer. Geriatr Gerontol Int. 2020;20(10):927-31. https://doi.org/1 $0.1111 /$ ggi.14016.

28. Bhat T, Teli S, Rijal J, Bhat H, Raza M, Khoueiry G, et al. Neutrophil to lymphocyte ratio and cardiovascular diseases: a review. Expert Rev Cardiovasc Ther. 2013;11(1):55-9. https://doi.org/10.1586/erc.12.159.

29. Kuyumcu ME, Yesil Y, Oztürk ZA, Kizilarslanoğlu C, Etgül S, Halil M, et al. The evaluation of neutrophil-lymphocyte ratio in Alzheimer's disease. Dement Geriatr Cogn Disord. 2012;34(2):69-74. https://doi.org/10.1159/000341583.

30. Gibson PH, Croal BL, Cuthbertson BH, Small GR, Ifezulike Al, Gibson G, et al. Preoperative neutrophil-lymphocyte ratio and outcome from coronary artery bypass grafting. Am Heart J. 2007;154(5):995-1002. https://doi.org/1 0.1016/j.ahj.2007.06.043.

31. Walsh SR, Cook EJ, Goulder F, Justin TA, Keeling NJ. Neutrophil-lymphocyte ratio as a prognostic factor in colorectal cancer. J Surg Oncol. 2005;91(3): 181-4. https://doi.org/10.1002/jso.20329.

32. Sarraf K, Belcher E, Raevsky E, Nicholson A, Goldstraw P, Lim E. Neutrophil/ lymphocyte ratio and its association with survival after complete resection in non-small cell lung cancer. J Thorac Cardiovasc Surg. 2009;137(2):425-8. https://doi.org/10.1016/j.jtcvs.2008.05.046.

33. Steinmetz J, Christensen KB, Lund T, Lohse N, Rasmussen LS, Grp I. Longterm consequences of postoperative cognitive dysfunction. Anesthesiology. 2009;110(3):548-55. https://doi.org/10.1097/ALN.0b013e318195b569.

34. Moller JT, Cluitmans P, Rasmussen LS, Houx P, Rasmussen H, Canet J, et al Long-term postoperative cognitive dysfunction in the elderly ISPOCD1 study. ISPOCD investigators. International Study of Post-Operative Cognitive Dysfunction. Lancet (London, England). 1998;351(9106):857-61.

35. Avidan MS, Evers AS. The fallacy of persistent postoperative cognitive decline. Anesthesiology. 2016;124(2):255-8. https://doi.org/10.1097/ALN. 0000000000000958

36. Fink HA, Hemmy LS, MacDonald R, Carlyle MH, Olson CM, Dysken MW, et al. Intermediate- and Long-Term Cognitive Outcomes After Cardiovascular Procedures in Older Adults A Systematic Review. Ann Intern Med. 2015; 163(2):107.

37. Cormack F, Shipolini A, Awad WI, Richardson C, McCormack DJ, Colleoni L, et al. A meta-analysis of cognitive outcome following coronary artery bypass graft surgery. Neurosci Biobehav Rev. 2012;36(9):2118-29. https://doi. org/10.1016/j.neubiorev.2012.06.002.

38. Seitz DP, Shah PS, Herrmann N, Beyene J, Siddiqui N. Exposure to general anesthesia and risk of alzheimer's disease: a systematic review and metaanalysis. BMC Geriatr. 2011;11(1):83. https://doi.org/10.1186/1471-2318-11-83.

\section{Publisher's Note}

Springer Nature remains neutral with regard to jurisdictional claims in published maps and institutional affiliations.
Ready to submit your research? Choose BMC and benefit from:

- fast, convenient online submission

- thorough peer review by experienced researchers in your field

- rapid publication on acceptance

- support for research data, including large and complex data types

- gold Open Access which fosters wider collaboration and increased citations

- maximum visibility for your research: over $100 \mathrm{M}$ website views per year

At BMC, research is always in progress.

Learn more biomedcentral.com/submissions 